\title{
Clinical Significance of Serum Levels of ROM (Reactive Oxygen Metabolites) in Patients With Rheumatoid Arthritis Treated With Biologic Agents as a Predictor for the CDAl-, SDAl-, and Boolean-Remission
}

Arata Nakajima ( $\square$ arata.nakajima@med.toho-u.ac.jp )

Toho University Sakura Medical Center

\section{Keiichiro Terayama}

Toho University Sakura Medical Center

\section{Masato Sonobe}

Toho University Sakura Medical Center

\section{Yorikazu Akatsu}

Toho University Sakura Medical Center

Junya Saito

Toho University Sakura Medical Center

\section{Masaki Norimoto}

Toho University Sakura Medical Center

\section{Shinji Taniguchi}

Toho University Sakura Medical Center

\section{Hiroshi Takahashi}

University of Tsukuba

\section{Yasuchika Aoki \\ Eastern Chiba Medical Center}

\section{Koichi Nakagawa}

Toho University Sakura Medical Center

\section{Research Article}

Keywords: reactive oxygen metabolites (ROM), biologic agents, rheumatoid arthritis, predictor, remission

Posted Date: June 24th, 2021

DOI: https://doi.org/10.21203/rs.3.rs-640054/v1

License: (c) (i) This work is licensed under a Creative Commons Attribution 4.0 International License. Read Full License 


\section{Abstract}

We previously showed that reactive oxygen metabolites (ROM) serum levels were associated with the DAS28 in patients with rheumatoid arthritis (RA). In this study, we aimed to investigate whether ROM would be predictive of the CDAI-, SDAl- or Boolean-remission. Fifty-one biologic agents (BA)-naïve RA patients were included in this observational study. Associations between ROM, C-reactive protein (CRP), MMP (matrix metalloproteinase)-3, DAS28-ESR, CDAI, SDAl, and health assessment questionnaire (HAQ) at 12 weeks and the DAS28-, CDAl-, SDAI-, and Boolean-remission at 52 weeks were investigated. The DAS28-, CDAl-, SDAl- and Boolean-remission rates at 52 weeks were 66.7, 52.9, 54.9 and 54.9\%, respectively. A multivariate logistic regression analysis revealed that ROM and HAQ at 12 weeks were associated with the CDAl-, SDAl- and Booleanremission at 52 weeks. Receiver operating characteristic (ROC) analyses demonstrated that the cut-off value for CDAI remission was 389.5 U.Carr, and that for SDAl and Boolean remission was 389.5 U.Carr. ROM at 12 weeks of initial treatment with BAs was a predictor for the CDAI-, SDAl-, and Boolean-remission at 52 weeks. Serum levels of ROM may be a useful biomarker in the current treatment strategy aiming at the early remission of RA.

\section{Introduction}

Rheumatoid arthritis (RA) is an autoimmune disease that induces synovial proliferation, leading to the development of joint destruction [1]. Oxidative stress induced by reactive oxygen species (ROS) is thought to be one of the key mechanisms that underlie joint destruction and synovial proliferation observed in RA [2-5]. Excessive production of ROS induces oxidative stress and damages proteins, lipids, and nucleic acids. Abundant amounts of ROS have been detected in the synovial fluid of inflamed joints in patients with RA [6], and ROS play a role as one of intracellular signaling molecules that amplify the synovial inflammation and proliferation [3]. Based on these observations, ROS are thought to be involved in the pathophysiology of RA, but their clinical significance in the treatment of RA remains unknown.

Recently, a method of measuring reactive oxygen metabolites (ROM) in blood, called the d-ROM test, has been developed. This method uses the Free Radical Analytical System 4 (FRAS 4, Wismarl, Italy) [7, 8]. Using this method, we previously showed that ROM serum levels were associated with C-reactive protein (CRP) and the disease activity score based on the examination of 28 joints (DAS28) in patients with RA [9]; however, their clinical significance as a biomarker during treatment of RA has not been elucidated fully.

To date, several factors have been reported to be associated with clinical remission during treatment [10-12]. Furthermore, novel biomarkers for predicting remission were identified $[13,14]$; however, their clinical significance in the treatment of RA remains unclear. Based on these perspectives, we hypothesized that measurement of ROM serum levels might be useful for checking current disease activity in the current treat-to-target strategy for RA. In this study, we investigated changes in ROM during treatment with BAs in patients classified as in remission and non-remission at 52 weeks, and verified whether ROM could predict the future remission by CDAl-, SDAl- and Boolean-standards that are stricter remission standards than DAS28 $[15,16]$.

\section{Methods}

\section{Patients and background characteristics}

In this observational study, 51 BA-naïve patients with RA (mean age, $61.0 \pm 13.6 \mathrm{y}$; disease duration, $7.24 \pm 11.0 \mathrm{y}$ ) were evaluated for ROM in addition to routine examinations. From patients who started treatment with tumor necrosis factor (TNF) inhibitors (infliximab, etanercept, adalimumab, golimumab, or certolizumab pegol) or tocilizumab from October 2011 to June 2016, blood samples were collected before administration of BAs and again at 4, 12, 24, and 52 weeks after initiation of administration. During this time, 46 patients had received one of the BAs listed above and had not been switched to other BAs. 
The background characteristics of patients included in this study are shown in Table 1. The 51 patients with RA were classified as follows: high disease activity $(n=18)$, moderate disease activity $(n=29)$, low disease activity $(n=3)$, or in remission ( $n=1)$. Overall, $88.2 \%$ of patients were treated with methotrexate (MTX, $8.78 \pm 1.47 \mathrm{mg} /$ week) and $68.6 \%$ with prednisolone (PSL, $5.54 \pm 2.48 \mathrm{mg} / \mathrm{day}$ ). Of the 51 patients, 22 received tocilizumab, and the others received TNF inhibitors (golimumab, 12; etanercept, 7; adalimumab, 4; certolizumab pegol, 4; and infliximab, 2). Five patients were switched to other BAs due to inadequate responses to their first BA: from golimumab to abatacept at 16- and 63weeks $(n=2)$, from golimumab to tocilizumab at 12- and 35-weeks $(n=2)$, and from tocilizumab to golimumab at 24weeks $(n=1)$.

Venous blood samples were collected and analyzed for serum CRP and matrix metalloproteinase-3 (MMP-3). In our hospital, the normal reference value for CRP is $0.3 \mathrm{mg} / \mathrm{dL}$. ROM was also measured as described below.

For the assessment of RA disease activity, measurements of DAS28-erythrocyte sedimentation rate (ESR), CDAl, and SDAI were obtained during the same visit at which the blood samples were collected. Remission based on the DAS28, CDAl, and SDAI were defined as when the scores were $\leq 2.6, \leq 2.8$, and $\leq 3.3$, respectively. Whether Boolean-remission was achieved or not was also checked. RA patients also completed the health assessment questionnaire (HAQ). Approval for the study was received from the Institutional Review Board at Toho University Sakura Medical Center, and all patients gave their written consent to participate in this study. All activities were performed in accordance with the ethical standards set forth in the Declaration of Helsinki.

\section{Measurement of oxidative stress markers in serum}

To measure ROM, the d-ROM test was performed using the FRAS 4 analyzer in accordance with the manufacturer's analytical procedures. The details were described in our previous publications [9]. Reference values indicated by the FRAS 4 manufacturer range up to 300 U.Carr; values $>300$ U.Carr suggest the presence of oxidative stress $[7,8]$.

\section{Statistical analyses}

Results are expressed as mean \pm standard deviation (SD). All laboratory data, DAS28, and HAQ scores were analyzed by the last-observation-carried-forward (LOCF) method. Between-group differences were assessed by the Mann Whitney U-test or Steel-Dwass method. A multivariate logistic regression analysis was performed by the stepwise method to compute the odds ratios (ORs) and $95 \%$ confidence intervals $(95 \% \mathrm{Cls})$ for achievement of remission at 52 weeks. All statistical analyses were performed using SPSS (ver. 19) software (SPSS, IL, USA), and $p$ values $<0.05$ were considered to indicate statistical significance.

\section{Results}

Changes in DAS28-ESR, CDAl, SDAl and remission rate during treatment

DAS28-ESR at baseline was $4.79 \pm 1.26$ and rapidly decreased to $2.87 \pm 1.23$ at 4 weeks. After 4 weeks, it gradually decreased to $2.29 \pm 1.78$ at 52 weeks (Fig. 1 A). The remission rate increased from baseline and reached $66.7 \%$ at 52 weeks (Fig. 1B). CDAl at baseline was $18.5 \pm 12.7$ and rapidly decreased to $7.30 \pm 5.60$ at 4 weeks. After 4 weeks, it gradually decreased to $5.83 \pm 11.9$ at 52 weeks (Fig. 1 A). The remission rate increased from baseline and reached $52.9 \%$ at 52 weeks (Fig. 1B). SDAl at baseline was $21.3 \pm 14.2$ and rapidly decreased to $8.07 \pm 6.45$ at 4 weeks. After 4 weeks, it gradually decreased to $6.45 \pm 13.2$ at 52 weeks (Fig. 1A). The remission rate increased from baseline and reached $54.9 \%$ at 52 weeks (Fig. 1B).

Changes in ROM serum levels in the remission and non-remission groups at 52 weeks of treatment 
As shown in Fig. 2, 33 patients achieved DAS28-remission at 52 weeks, while 18 did not. For CDAl remission, 27 patients achieved it, but 24 patients did not. The distribution of patients with SDAl- and Boolean-remission was the same: 28 patients achieved remission, but 23 patients did not. Overall, ROM serum levels in both the remission and non-remission groups decreased between baseline and 4 weeks and remained low thereafter. In the remission group, there was a significant reduction in ROM after 4 weeks compared to baseline levels $(p<0.05)$. In the non-remission group, significant reduction was also seen after 4 weeks based on the CDAl, SDAl, and Boolean standards, but not at 4, 24, and 52 weeks based on the DAS28 standard.

Analyses to identify factors at 12 weeks of treatment that are associated with 52-week remission

Since temporal changes in ROM in the remission and non-remission groups at 52 weeks followed different patterns after 12 weeks, we elected to analyze factors at 12 weeks that may be associated with 52 -week remission. We performed a univariate analysis for variables including ROM, CRP, MMP-3, DAS28, CDAI, SDAl, and HAQ at 12 weeks between the 52week remission and non-remission groups. For DAS28 remission, ROM, MMP-3, DAS28, CDAI, SDAl, and HAQ were significantly different. For CDAl-, SDAl-, and Boolean-remission, ROM, DAS28, CDAI, SDAl, and HAQ were significantly different $(p<0.05$, Table 2$)$.

A multivariate logistic regression analysis revealed the following: (1) DAS28 was associated with the DAS28-remission (OR: 0.172, 95\% Cl: 0.063-0.467, $p=0.001)$; (2) ROM and HAQ were associated with the CDAl-remission (OR: 0.991; 95\% Cl: 0.983-0.999, $p=0.029$ for ROM; OR: 0.102, 95\% Cl: 0.017-0.605, $p=0.012$ for HAQ); and (3) ROM and HAQ were also associated with the SDAl- and Boolean-remission (OR: 0.989, 95\% Cl: 0.980-0.997, $p=0.011$ for ROM; OR: 0.166, 95\% Cl: $0.031-0.889, p=0.036$ for HAQ) (Table 3). As shown in Fig. 3A, for the CDAl-remission, the area under the curve (AUC) of the receiver operating characteristic (ROC) curve for ROM (blue line) was 0.696 (sensitivity: $50.0 \%$, specificity: $92.3 \%$ ). For the SDAl- and Boolean-remission, it was 0.737 (sensitivity: $52.2 \%$, specificity: $92.6 \%$ ). The cut-off value that discriminated remission from non-remission for CDAI, SDAI and Boolean standards was determined to be 389.5 U.Carr.

We further analyzed the correlation between ROM at 12 weeks and CDAI or SDAI at 52 weeks, and found that ROM at 12 weeks was correlated with $\operatorname{CDAl}(r=0.473, p<0.01)$ and SDAI $(r=0.508, p<0.01)$ (Fig. 3B). We also analyzed the correlation between ROM at baseline and CDAI or SDAI at 52 weeks; however, no significant correlations were detected (data not shown).

\section{Discussion}

In this study, we demonstrated that the ROM serum level at 12 weeks in the treatment with BAs was a useful biomarker for predicting the 52-week remission for CDAI, SDAl, and Boolean standards. The HAQ at 12 weeks was also a predictor for the 52-week remission. The AUC values of ROM for the CDAl-remission and SDAl- or Boolean-remission were 0.696 and 0.737, respectively, both of which were moderately accurate; those of HAQ were 0.743 and 0.712 , respectively, which were almost equivalent to those of ROM. The sensitivity for the CDAl-remission and SDAl-or Boolean-remission were $50.0 \%$ and $52.2 \%$, respectively, although their specificity was over $90 \%$. Considering these results, at present, ROM may not be a highly accurate predictor for the 52-week remission for CDAI, SDAI and Boolean standards. However, CRP and MMP-3, which are biomarkers used to monitor disease activity and joint damage progression in a routine clinical practice, were not identified as predictors for the 52-week remission in a logistic regression analysis. These results suggest that ROM is at least superior to $\mathrm{CRP}$ and MMP-3 in terms of predicting future remission.

It seems important to determine the appropriate time point during treatment for predicting 52-week remission. In addition to 12 weeks, we investigated whether the ROM serum level at baseline and at 4 weeks could predict 52-week remission in a logistic regression analysis, but we could not find significant factors (data not shown). Therefore, we decided that 12 weeks was the appropriate time point to measure ROM serum levels for predicting 52-week remission. The finding that the ROM 
level at 12 weeks can predict the 52-week remission for CDAI, SDAI and Boolean standards could make ROM a useful biomarker for monitoring current treatment strategies relatively early.

Previous studies have demonstrated that the baseline HAQ was associated with remission after treatment. Quintana-Duque et al showed that a lower HAQ-disability index (DI) score and absence of autoantibodies were predictive of remission [10]. Hoshi et al showed that the baseline Japanese version of HAQ was a negative predictor of Boolean-based remission in patients treated with tocilizumab [11]. Pomirleanu et al showed that initial DAS28-ESR, HAQ-DI, CRP, rheumatoid factor (RF), and anti-citrullinated protein antibody (ACPA) were associated with an increased likelihood of remission and low disease activity [17]. These findings suggest that the baseline HAQ could be a useful parameter for predicting remission. Actually, in the present study, the HAQ and ROM were identified as factors associated with the 52-week remission. However, the HAQ is in itself a parameter to check functional disabilities rather than a biomarker. From the viewpoint of biomarkers for monitoring treatment progress, ROM seems to be superior to HAQ.

In this study, the distribution of patients with CDAl-remission was the same as that of patients with SDAl-and Booleanremission except for one patient. This leads to quite similar results, which are shown in Tables 2 and 3 and Figs. 1-3, between the remission and non-remission groups for CDAI and SDAI or Boolean standards. Because we used tocilizumab for approximately $40 \%(22 / 51)$ of patients, the SDAI and Boolean standards, which are affected by CRP, might have been evaluated better. If we used TNF-inhibitors for more patients, the distribution of patients for CDAl-remission and SDAl- or Boolean-remission may be altered.

A predictive factor for DAS28 remission was DAS28 at 12 weeks; however, this is an expected result. The serum ROM levels were not identified $(p=0.056)$. When DAS28 was excluded from independent variables, ROM and HAQ were again identified (OR: $0.985,95 \% \mathrm{Cl}: 0.975-0.995, p=0.005$ for ROM; OR: $0.075,95 \% \mathrm{Cl}: 0.010-0.570, p=0.012$ for HAQ, data not shown). DAS28 may differ among physicians and also is not a biomarker. Therefore, we believe that monitoring ROM values allows physicians to predict future remission rather than monitoring DAS28.

The strong points of this study are that we demonstrated the superiority of ROM to other clinical parameters used in routine clinical practice, such as CRP, MMP-3, DAS28, CDAl, and SDAl, as a predictor for the 52-week remission by CDAI, SDAI and Boolean standards. Although the ROM cut-off value that discriminates remission from non-remission does not have high sensitivity, controlling serum ROM levels tightly may allow patients to achieve remission by CDAI, SDAI and Boolean standards in the early stage during treatment with BAs.

This study has some limitations. First, the sample size was small, and background characteristics such as disease duration, PSL and MTX doses, and concomitant diseases varied among patients. Second, a variety of BAs, including TNF inhibitors and tocilizumab, were used. The effect of BAs on the inhibition of ROM may be different among BAs. Third, association of ROM with joint destruction has not been investigated. The relationship between serum ROM levels and radiographic progression of joint damage should be analyzed in the future. Fourth, although oxidative stress is involved in the pathophysiology of many diseases in humans [18-23], its role in the pathobiology of RA remains unclear. Further studies are required to establish the clinical significance of oxidative stress in RA.

In conclusion, the ROM serum level at 12 weeks after treatment initiation with BAs is a predictive factor of 52-week remission by CDAI, SDAI and Boolean standards. The ROM serum level may be a useful biomarker for achieving early remission in the current treatment strategy aiming at the early remission of RA.

\section{Declarations}

Ethics approval and consent to participate: Approval for the study was received from the Institutional Review Board at Toho University Sakura Medical Center, and all patients gave their written consent to participate in this study. All activities were performed in accordance with the ethical standards set forth in the Declaration of Helsinki. 
Consent for publication: All patients gave their written consent to publish to report individual patient data.

Availability of data and materials: The datasets used and/or analyzed during the current study are available from the corresponding author on reasonable request.

Competing interests: The authors declare that they have no competing interest.

Funding: This study was supported by a Grant-in-Aid for Scientific Research of Japan Society for the Promotion of Science (20K09469 to A.N.).

Authors' contributions: A.N participated in the design of the study, performed the statistical analysis and drafted the manuscript. K.T and H.T participated in the design of the study and performed statistical analyses. M.S and J.S participated in the design of the study and helped to draft the manuscript. Yo.A, M.N and S.T collected patients' clinical information and made a part of figures and tables. Ya.A and K.N conceived of the study, participated in its design and coordination and helped to revise the manuscript. All authors read and approved the final manuscript.

Acknowledgements: Not applicable

\section{References}

1. Pap T, Muller-Ladner U, Gay RE, Gay S. Fibroblast biology: role of synovial fibroblasts in the pathogenesis of rheumatoid arthritis. Arthritis Res. 2, 361-367 (2000).

2. Mapp PI, Grootveld MC, Blake DR. Hypoxia, oxidative stress, and rheumatoid arthritis. Br. Med. Bull. 51, $419-436$ (1995).

3. Hitchon CA, El-Gabalawy H. Oxidation in rheumatoid arthritis. Arthritis Res. Ther. 6, 265-278 (2004).

4. Halliwell B. Oxygen radicals, nitric oxide, and human inflammatory joint disease. Ann. Rheum. Dis. 54, 505-510 (1995).

5. Tak PP, Zvaifler NJ, Grenn DR, Firestein GS. Rheumatoid arthritis and p53: how oxidative stress might alter the course of inflammatory diseases. Immunol. Today. 21, 78-82 (2000).

6. Biemond P, Swaak AJ, Koster JF. Protective factors against oxygen free radicals and hydrogen peroxide in rheumatoid arthritis synovial fluid. Arthritis Rheum. 27, 760-765 (1984).

7. Carratelli M, Porcaro L, Ruscica M, De Simone E, Bertelli AA, Corsi MM. Reactive oxygen metabolites and prooxidant status in children with Down's syndrome. Int. J. Clin. Pharm. Res. 21, 79-84 (2001).

8. Trotti R, Carratelli M, Barbieri M, Micieli G, Bosone D, Rondanelli M, Bo P. Oxidative stress and a thrombophilic condition in alcoholics without severe liver disease. Haematologica. 86, 85-91 (2001).

9. Nakajima A, Aoki Y, Shibata Y, Sonobe M, Terajima F, Takahashi H, Saito M, Taniguchi S, Yamada M, Nakagawa K. Identification of clinical parameters associated with serum oxidative stress in patients with rheumatoid arthritis. Mod. Rheumatol. 6, 926-930 (2014).

10. Quintana-Duque MA, Rondon-Herrera F, Mantilla RD, Calvo-Paramo E, Yunis JJ, Varela-Nariño A, Restrepo JF, IglesiasGamarra A. Predictors of remission, erosive disease and radiographic progression in a Colombian cohort of early onset rheumatoid arthritis: a 3-year follow-up study. Clin. Rheumatol. 6, 1463-1473 (2016).

11. Hoshi D, Nakajima A, Shidara K, Seto Y, Tanaka E, Taniguchi A, Momohara S, Yamanaka H. Disability is the major negative predictor for achievement of Boolean-based remission in patients with rheumatoid arthritis treated with tocilizumab. Mod. Rheumatol. 23, 1205-1210 (2013).

12. Shiozawa K, Yamane T, Murata M, Yoshihara R, Tsumiyama K, Imura S, Shiozawa S. MMP-3 as a predictor for structural remission in RA patients treated with MTX monotherapy. Arthritis Res. Ther. 18, 55. 10.1186/s13075-0160948-7 (2016).

13. Shen J, Shang Q, Wong CK, Li EK, Wang S, Li RJ, Lee KL, Leung YY, Ying KY, Yim CW, Kun EW, Leung MH, Li M, Li TK, Zhu TY, Yu SL, Kuan WP, Yu CM, Tam LS. IL-33 and soluble ST2 levels as novel predictors for remission and 
progression of carotid plaque in early rheumatoid arthritis: A prospective study. Semin. Arthritis Rheum. 45, 18-27 (2015).

14. Ammitzbøll CG, Thiel S, Jensenius JC, Ellingsen T, Hørslev-Petersen K, Hetland ML, Junker P, Krogh NS, Østergaard M, Stengaard-Pedersen K. M-ficolin levels reflect disease activity and predict remission in early rheumatoid arthritis. Arthritis Rheum. 65:3045-3050 (2013).

15. Sheehy C, Evans V, Hasthorpe H, Mukhtyar C. Revising DAS28 scores for remission in rheumatoid arthritis. Clin. Rheumatol. 33, 269-72 (2014).

16. Gaujoux-Viala C, Mouterde G, Baillet A, Claudepierre P, Fautrel B, Le Loët X, Maillefert JF. Evaluating disease activity in rheumatoid arthritis: which composite index is best? A systematic literature analysis of studies comparing the psychometric properties of the DAS, DAS28, SDAI and CDAI. Joint Bone Spine. 79, 149-55 (2012).

17. Pomirleanu C, Ancuta C, Miu S, Chirieac R. A predictive model for remission and low disease activity in patients with established rheumatoid arthritis receiving TNF blockers. Clin. Rheumatol. 32, 665-670 (2013).

18. Faienza MF, Francavilla R, Goffredo R, Ventura A, Marzano F, Panzarino G, Marinelli G, Cavallo L, Di Bitonto G. Oxidative stress in obesity and metabolic syndrome in children and adolescents. Horm. Res. Paediatr. 78, 158-64 (2012).

19. Coaccioli S, Standoli ML, Biondi R, Panaccione A, Landucci P, Del Giorno R, Paladini A, Standoli M, Puxeddu A. Assessment of the oxidative stress markers in patients with chronic renal insufficiency undergoing dialysis treatment. Clin. Ter. 161, 441-444 (2010).

20. Koutsokera A, Papaioannou Al, Malli F, Kiropoulos TS, Katsabeki A, Kerenidi T, Gourgoulianis KI, Daniil ZD. Systemic oxidative stress in patients with pulmonary sarcoidosis. Pulm. Pharmacol. Ther. 22, 603-607 (2009).

21. Suzuki S, Matsukura S, Takeuchi H, Kawaguchi M, leki K, Odaka M, Watanabe S, Homma T, Dohi K, Aruga T, Sato M, Kurokawa M, Kokubu F, Adachi M. Increase in reactive oxygen metabolite level in acute exacerbations of asthma. Int. Arch. Allergy Immunol. 146 Suppl 1, 67-72 (2008).

22. Kotani K, Koibuchi H, Miyamoto M, Yamada T, Taniguchi N. Relationship between reactive oxygen metabolites and carotid intima-media thickness in subjects with hypercholesterolemia. Med. Princ. Pract. 19, 496-498 (2010).

23. Yamanaka G, Kawashima H, Suganami Y, Watanabe C, Watanabe Y, Miyajima T, Takekuma K, Oguchi S, Hoshika A. Diagnostic and predictive value of CSF d-ROM level in influenza virus-associated encephalopathy. J. Neurol. Sci. 243, 71-75 (2006).

\section{Tables}

Table 1. Patients' demographic and disease characteristics at baseline 


\begin{tabular}{|ll|}
\hline Number of patients & 51 \\
\hline Age, years (range) & $61.0 \pm 13.6(21-80)$ \\
\hline Height, cm & $157.1 \pm 6.8$ \\
\hline Body weight, kg & $55.9 \pm 9.4$ \\
\hline BMI, kg/m ${ }^{2}$ & $22.6 \pm 3.6$ \\
\hline Disease duration, years (range) & $7.24 \pm 11.0(1-52)$ \\
\hline RF-positive (\%) & 72.5 \\
\hline ROM, U.Carr (range) & $556 \pm 123(308-860)$ \\
\hline CRP, mg/dL & $2.82 \pm 3.09$ \\
\hline MMP-3, ng/mL & $397 \pm 354$ \\
\hline DAS28-ESR & $4.79 \pm 1.26$ \\
\hline CDAl & $18.46 \pm 12.74$ \\
\hline SDAl & $21.26 \pm 14.21$ \\
\hline TJC & $5.6 \pm 5.9$ \\
\hline SJC & $4.2 \pm 5.1$ \\
\hline PTGA, mm & $45.1 \pm 24.2$ \\
\hline MDGA, mm & $45.5 \pm 21.9$ \\
\hline HAQ & $0.791 \pm 0.610$ \\
\hline PSL, mg/day (\% usage) & $5.54 \pm 2.48$ (68.6) \\
\hline MTX, mg/week (\% usage) & $8.78 \pm 1.47$ (88.2) \\
\hline Biologic agents & 22 \\
\hline Tocilizumab & 12 \\
\hline Golimumab & \\
\hline Etanercept & \\
\hline Adalimumab & \\
\hline Certolizumab pegol & \\
\hline Infliximab & \\
\hline
\end{tabular}

BMI: body mass index, RF: rheumatoid factor, ROM: reactive oxygen metabolites, CRP: C-reactive protein, MMP-3: matrix metalloproteinase-3, DAS28: 28-joint disease activity score, ESR: erythrocyte sedimentation rate, SDAl: simplified disease activity index, CDAl: clinical disease activity index, TJC: tender joint count, SJC: swollen joint count, PTGA: patient's global assessment, MDGA: medical doctor's global assessment, HAQ: health assessment questionnaire, PSL: prednisolone, MTX: methotrexate. 
Table 2. Comparison of the factors at 12 weeks between the remission and non-remission groups at 52 weeks

\begin{tabular}{|c|c|c|c|c|c|c|c|c|c|}
\hline & \multicolumn{3}{|l|}{ DAS28 } & \multicolumn{3}{|l|}{ CDAI } & \multicolumn{3}{|c|}{ SDAI \& Boolean } \\
\hline & $\begin{array}{l}\text { Remission } \\
\mathrm{N}=33\end{array}$ & $\begin{array}{l}\text { Non- } \\
\text { remission } \\
\mathrm{N}=18\end{array}$ & $p$ & $\begin{array}{l}\text { Remission } \\
N=27\end{array}$ & $\begin{array}{l}\text { Non- } \\
\text { remission } \\
N=24\end{array}$ & $p$ & $\begin{array}{l}\text { Remission } \\
\mathrm{N}=28\end{array}$ & $\begin{array}{l}\text { Non- } \\
\text { remission } \\
\mathrm{N}=23\end{array}$ & $p$ \\
\hline $\begin{array}{l}\text { ROM } \\
\text { (U.Carr) }\end{array}$ & $\begin{array}{l}306 \pm \\
72.5\end{array}$ & $\begin{array}{l}434 \pm \\
131\end{array}$ & $0.001 *$ & $\begin{array}{l}307 \pm \\
61.4\end{array}$ & $\begin{array}{l}396 \pm \\
138\end{array}$ & $0.007 *$ & $\begin{array}{l}302 \pm \\
65.2\end{array}$ & $\begin{array}{l}405 \pm \\
132\end{array}$ & $0.002 *$ \\
\hline $\begin{array}{l}\text { CRP } \\
(\mathrm{mg} / \mathrm{dL})\end{array}$ & $\begin{array}{l}0.052 \pm \\
0.13\end{array}$ & $\begin{array}{l}1.53 \pm \\
2.98\end{array}$ & 0.057 & $\begin{array}{l}0.087 \pm \\
0.21\end{array}$ & $\begin{array}{l}1.06 \pm \\
2.59\end{array}$ & 0.079 & $\begin{array}{l}0.084 \pm \\
0.21\end{array}$ & $\begin{array}{l}1.11 \pm \\
2.64\end{array}$ & 0.077 \\
\hline $\begin{array}{l}\text { MMP3 } \\
\text { (ng/mL) }\end{array}$ & $\begin{array}{l}100 \pm \\
73.4\end{array}$ & $\begin{array}{l}198 \pm \\
157\end{array}$ & $0.029 *$ & $\begin{array}{l}105 \pm \\
68.1\end{array}$ & $\begin{array}{l}160 \pm \\
147\end{array}$ & 0.103 & $\begin{array}{l}105 \pm \\
66.9\end{array}$ & $\begin{array}{l}164 \pm \\
150\end{array}$ & 0.090 \\
\hline $\begin{array}{l}\text { DAS28- } \\
\text { ESR }\end{array}$ & $\begin{array}{l}1.75 \pm \\
0.900\end{array}$ & $\begin{array}{l}3.95 \pm \\
1.76\end{array}$ & $0.000 *$ & $\begin{array}{l}1.86 \pm \\
1.10\end{array}$ & $\begin{array}{l}3.18 \pm \\
1.83\end{array}$ & $0.004^{*}$ & $\begin{array}{l}1.85 \pm \\
1.08\end{array}$ & $\begin{array}{l}3.26 \pm \\
1.84\end{array}$ & $0.003 *$ \\
\hline CDAI & $\begin{array}{l}3.87 \pm \\
4.62\end{array}$ & $\begin{array}{l}14.2 \pm \\
17.8\end{array}$ & $0.031^{*}$ & $\begin{array}{l}3.86 \pm \\
5.05\end{array}$ & $\begin{array}{l}11.2 \pm \\
15.7\end{array}$ & $0.037 *$ & $\begin{array}{l}3.86 \pm \\
4.96\end{array}$ & $\begin{array}{l}11.5 \pm \\
16.0\end{array}$ & $0.036^{*}$ \\
\hline SDAI & $\begin{array}{l}3.99 \pm \\
4.68\end{array}$ & $\begin{array}{l}15.7 \pm \\
20.3\end{array}$ & $0.031 *$ & $\begin{array}{l}4.03 \pm \\
5.14\end{array}$ & $\begin{array}{l}12.3 \pm \\
17.9\end{array}$ & $0.039 *$ & $\begin{array}{l}4.03 \pm \\
5.05\end{array}$ & $\begin{array}{l}12.6 \pm \\
18.2\end{array}$ & $0.038^{*}$ \\
\hline HAQ & $\begin{array}{l}0.254 \pm \\
0.353\end{array}$ & $\begin{array}{l}0.824 \pm \\
0.754\end{array}$ & $0.008^{*}$ & $\begin{array}{l}0.212 \pm \\
0.318\end{array}$ & $\begin{array}{l}0.703 \pm \\
0.697\end{array}$ & $0.003^{*}$ & $\begin{array}{l}0.245 \pm \\
0.358\end{array}$ & $\begin{array}{l}0.685 \pm \\
0.707\end{array}$ & $0.011 *$ \\
\hline
\end{tabular}

ROM: reactive oxygen metabolites, CRP: C-reactive protein; MMP-3: matrix metalloproteinase-3, DAS28: 28-joint disease activity score, CDAl: clinical disease activity index, SDAl: simplified disease activity index, HAQ: health assessment questionnaire. *Significantly different between groups $(p<0.05)$.

Table 3. A multivariate logistic regression analysis determining factors at 12 weeks of treatment associated with the 52-week remission

\begin{tabular}{|c|c|c|c|c|c|c|c|c|c|}
\hline & \multicolumn{3}{|l|}{ DAS28 } & \multicolumn{3}{|l|}{ CDAl } & \multicolumn{3}{|c|}{ SDAI \& Boolean } \\
\hline & $\begin{array}{l}\text { Odds } \\
\text { ratio }\end{array}$ & $95 \% \mathrm{Cl}$ & $p$ & $\begin{array}{l}\text { Odds } \\
\text { ratio }\end{array}$ & $95 \% \mathrm{Cl}$ & $p$ & $\begin{array}{l}\text { Odds } \\
\text { ratio }\end{array}$ & $95 \% \mathrm{Cl}$ & $p$ \\
\hline ROM & 0.992 & $\begin{array}{l}0.976- \\
1.007\end{array}$ & 0.056 & 0.991 & $\begin{array}{l}0.983- \\
0.999\end{array}$ & $0.029 *$ & 0.989 & $\begin{array}{l}0.980- \\
0.997\end{array}$ & $0.011 *$ \\
\hline $\begin{array}{l}\text { DAS28- } \\
\text { ESR }\end{array}$ & 0.172 & $\begin{array}{l}0.063- \\
0.467\end{array}$ & $0.001 *$ & 0.879 & $0.31-2.497$ & 0.774 & 0.91 & $\begin{array}{l}0.320- \\
2.585\end{array}$ & 0.859 \\
\hline CDAI & 0.85 & $\begin{array}{l}0.041- \\
17.57\end{array}$ & 0.228 & 0.581 & $\begin{array}{l}0.063- \\
5.339\end{array}$ & 0.782 & 0.551 & $\begin{array}{l}0.054- \\
5.683\end{array}$ & 0.617 \\
\hline SDAI & 1.326 & $\begin{array}{l}0.062- \\
28.25\end{array}$ & 0.232 & 1.722 & $\begin{array}{l}0.185- \\
16.013\end{array}$ & 0.800 & 1.74 & $\begin{array}{l}0.167- \\
18.108\end{array}$ & 0.643 \\
\hline HAQ & 0.027 & $\begin{array}{l}0.001- \\
1.053\end{array}$ & 0.222 & 0.102 & $\begin{array}{l}0.017- \\
0.605\end{array}$ & $0.012^{\star}$ & 0.166 & $\begin{array}{l}0.031- \\
0.889\end{array}$ & $0.036^{*}$ \\
\hline
\end{tabular}

ROM: reactive oxygen metabolites, DAS28: 28-joint disease activity score, ESR: CDAl: clinical disease activity index, SDAl: simplified disease activity index, HAQ: health assessment questionnaire, Cl: confidence interval. *Significant differences according to a logistic regression analysis $(p<0.05)$. 
DAS28-ESR

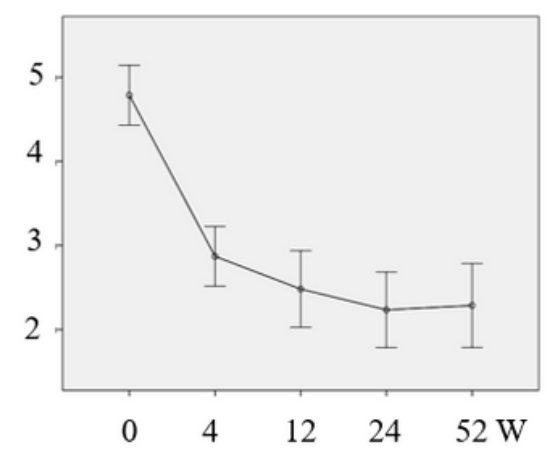

(A)

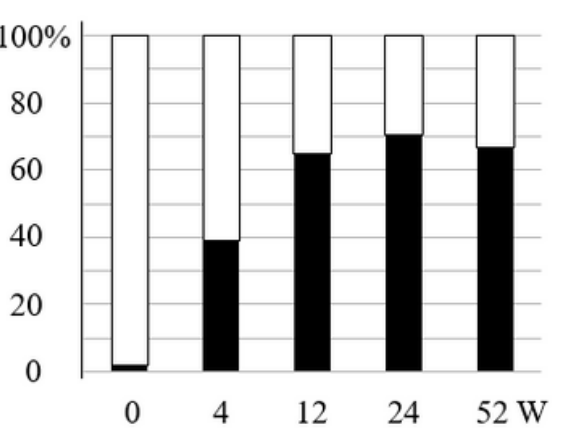

(B)
CDAI
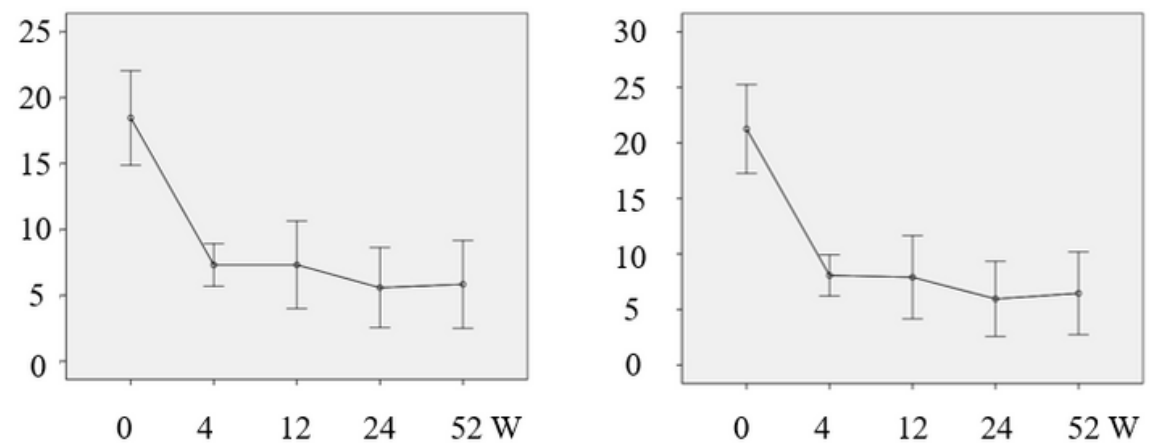

SDAI
Remission

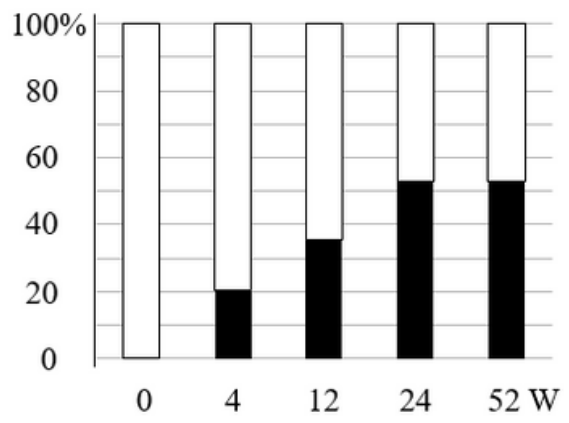

$\square$ Non-remission

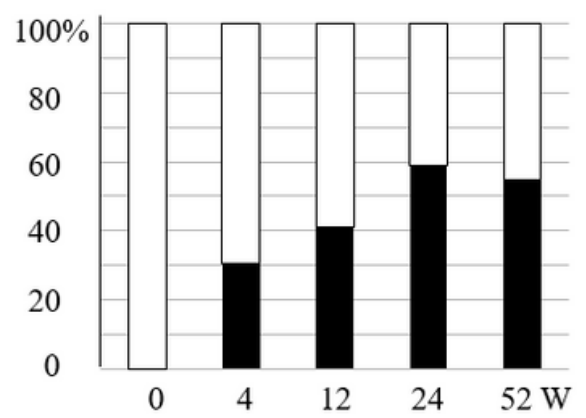

Figure 1

Figure 1

Changes in DAS28-ESR, CDAl, and SDAI (A) and the remission rate (B) for all patients $(n=51)$ from baseline to 52 weeks. Error bars indicate \pm SD. DAS28-ESR: disease activity score-28 with erythrocyte sedimentation rate, CDAl: clinical disease activity index, SDAl: simplified disease activity index. 


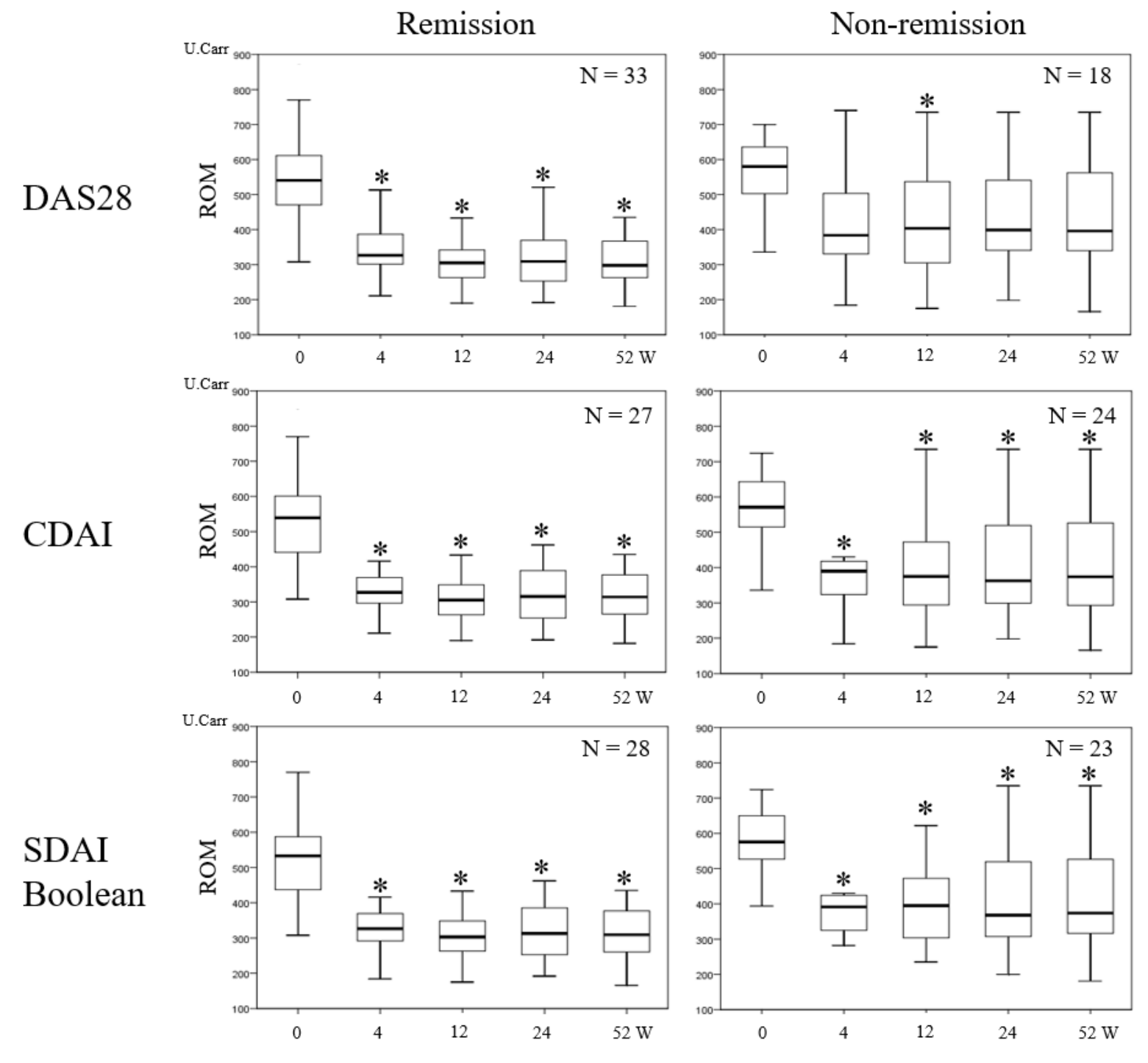

Figure 2

Figure 2

Changes in the serum level of ROM in the 52-week remission and non-remission groups. The distribution of patients with SDAl- and Boolean-remission was the same. Overall, the ROM serum levels in both the remission and non-remission groups decreased between baseline and 4 weeks and remained low thereafter. In the remission group, there was a significant reduction in ROM after 4 weeks compared to baseline levels $(p<0.05)$. In the non-remission group, significant reduction was also seen after 4 weeks, but not at 4, 24, and 52 weeks based on the DAS28 standard. Thick horizontal line: median value; box: interquartile range (IQR); whiskers: most extreme points within 1.5-times the IQR from the limits of the box. Asterisks show significant differences compared to baseline values ( $\left.{ }^{*} \mathrm{p}<0.05\right)$. ROM: reactive oxygen metabolites. 
CDAI

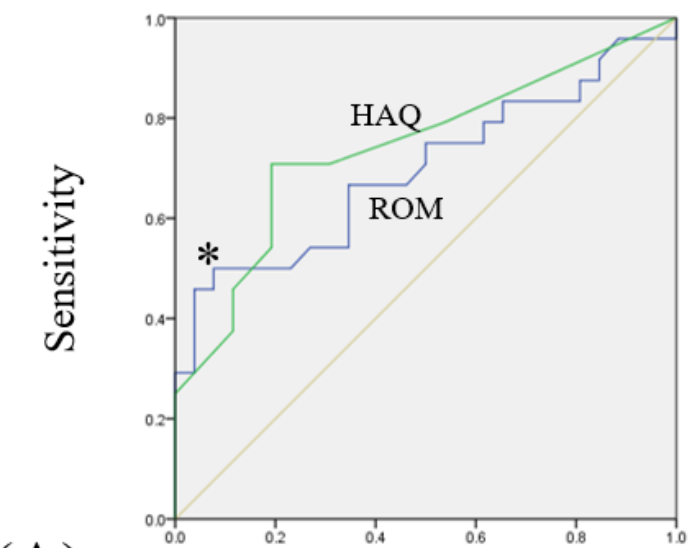

SDAI \& Boolean

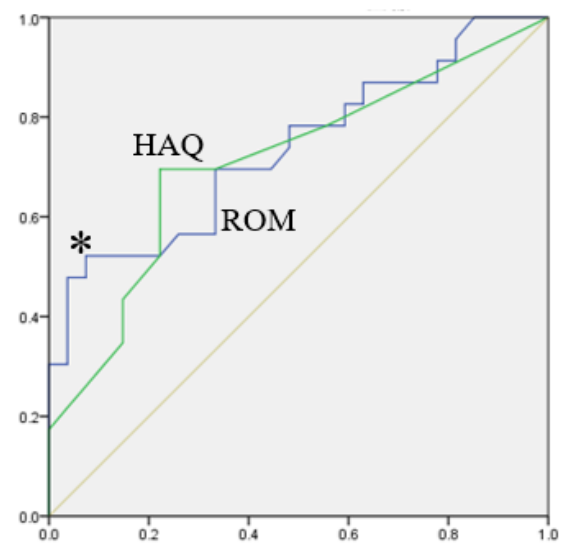

1-Specificity

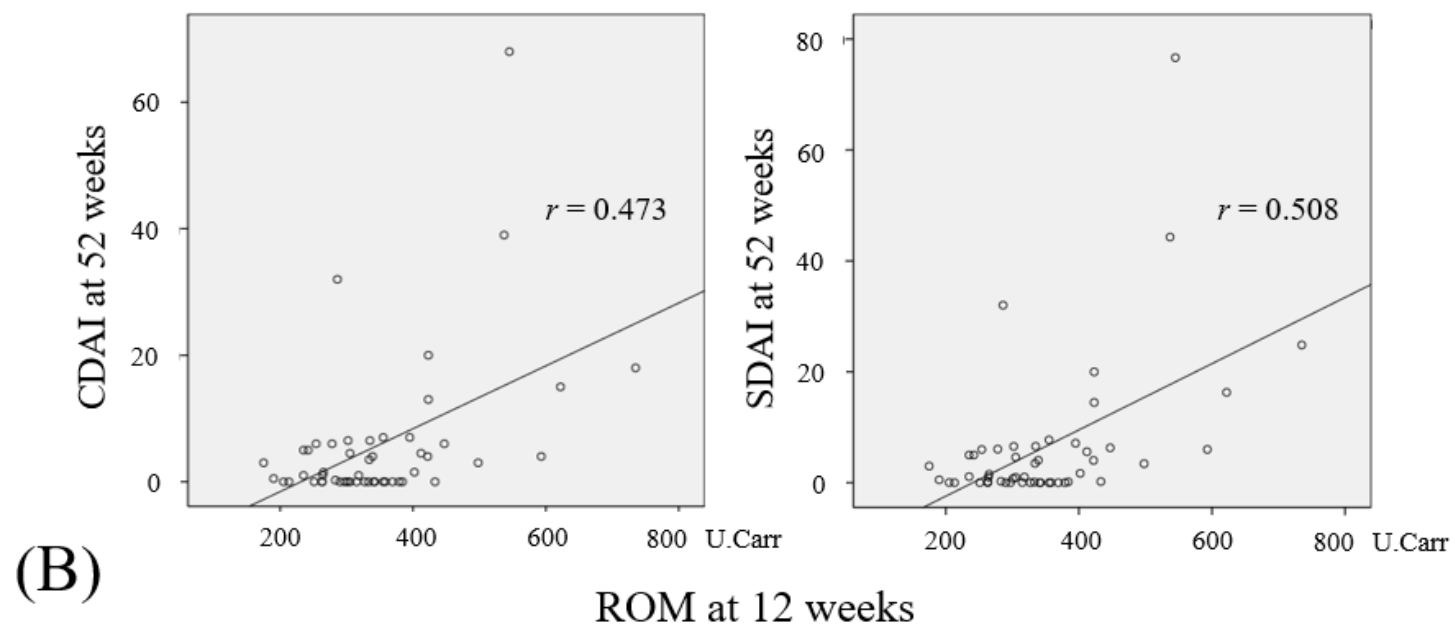

Figure 3

Figure 3

(A) ROC curves for ROM (blue line) and HAQ (green line) at 12 weeks predicting the CDAI-, SDAl-, and Boolean-remission at 52 weeks. The cut-off value for ROM corresponds to 389.5 U.Carr (indicated as an asterisk). (B) Correlation between ROM at 12 weeks and CDAl or SDAl at 52 weeks. CDAl and SDAl at 52 weeks were correlated with ROM at 12 weeks $(r=0.473, p<$ 0.01 for CDAl; $r=0.508, p<0.01$ for SDAl). ROC: receiver operating characteristic; ROM: reactive oxygen metabolites. 